\section{Prevalence of visual impairment in adults with intellectual disabilities in the Netherlands: cross- sectional study}

J van Splunder ${ }^{1,2}$, JS Stilma1', RMD Bernsen² and HM Evenhuis ${ }^{2}$
'Department of Ophthalmology, University Medical Centre, Utrecht, The Netherlands

${ }^{2}$ Intellectual Disability Medicine, Department of General Practice/Erasmus MC-University Medical Centre Rotterdam, The Netherlands

Correspondence: JS Stilma, Department of

Ophthalmology, University Medical Centre, Utrecht, E03.136, Heidelberglaan 100, Utrecht 3584 CX, The Netherlands Tel: + 3130250 9111; Fax: + 31302505417 E-mail: J.Stilma@ azu.nl

Received: 2 March 2005 Accepted in revised form: 6 July 2005

Published online:

9 September 2005

\begin{abstract}
Purpose To obtain the first representative and valid population-based prevalence figures on visual impairment and blindness in adults with intellectual disabilities (ID) and to identify risk groups.

Methods Study design: Cross-sectional survey. An age-Down's syndrome-stratified random sample of $\mathbf{1 5 9 8}$ persons from a base population of 9012 adult users of ID services with mild to profound intellectual disabilities was screened. Participants underwent protocollised on-site screening of visual functions. Results were related to degree of ID, occurrence of Down's syndrome (DS) and age. Main outcome measure: Prevalences of visual impairment and blindness in the study population and in subgroups and weighted prevalences in the total Dutch population using ID services.

Results Prevalences of visual impairment ranged from $2.2 \%$ (95\% confidence interval (CI), 0.5-6.4) in young adults with mild ID and no Down's syndrome to $66.7 \%$ (95\% CI, $41.0-$ 86.7) in older adults with profound ID and Down's syndrome; prevalences of blindness ranged from $0.7 \%(95 \% \mathrm{CI}, 0.1-4.1)$ to $38.9 \%$ (95\% CI, 28.1-50.3). Weighted prevalences of visual impairment and blindness in the total Dutch population of adult users of intellectual disabity services are $13.8 \%$ (95\% CI, 9.3-18.4) and $5.0 \%$ (95\% CI, 3.8-6.2), respectively. Prior to this study, visual impairment or blindness had remained undiagnosed in 106/261 (40.6\%) persons.

Conclusions As compared to published figures for the general Dutch population aged 55 years and over (visual impairment 1.4\%, blindness $0.5 \%$ ), prevalences of visual impairment and blindness are higher in all
\end{abstract}

subgroups with intellectual disabilities, including the young and mildly handicapped group. The diagnosis is too often missed. All persons with severe or profound intellectual disabilities, and all older adults with Down's syndrome, should be considered visually impaired until proved otherwise.

Eye (2006) 20, 1004-1010. doi:10.1038/sj.eye.6702059; published online 9 September 2005

Keywords: visual impairment; intellectual disability; risk factors; Down's syndrome; age; epidemiology

\section{Introduction}

In the last decades, the awareness has grown that people with intellectual disabilities (ID) may have a higher risk of visual impairment. ${ }^{1}$ However, it is still not known whether the whole ID-population, including young people with mild ID, by far the largest subgroup, has a higher risk of visual impairment, or whether this risk is limited to specific subgroups. Early investigations either covered small or selected adult groups or were collected from (incomplete) registrations. ${ }^{2-4}$ In more recent studies, assessing larger adult populations, ${ }^{5-10}$ samples were still selected and never large enough for statistical evaluation of subgroups. Epidemiological research of visual impairment in children with ID is scarce. ${ }^{11}$ As a result, until now, no valid figures are available to serve as a basis for national health policies and the provision of specific low-vision services. This first population-based large-scale epidemiological study of visual and hearing impairment, covering 1598 adult users of intellectual disability services, both residential 
and daycare, was recently completed. The results of our investigation of ocular pathology in the study population have recently been published. ${ }^{12}$

The purpose of this article is to report the results of the screening of visual function, in order to answer the following questions:

i What are the prevalences of visual impairment and blindness in adults with ID?

ii How are these prevalences related to age, the presence of Down's syndrome and severity of ID?

iii What is the result of generalisation of the study results to the total adult population with ID in the Netherlands?

\section{Patients and methods}

\section{Population}

The sampling and inclusion procedures have previously been described in detail. ${ }^{12,13}$ A random sample of 2100 clients was drawn from a representative base population of 9012 clients of Dutch intellectual disability services, both residential and day care. The small subgroup with Down's syndrome aged 50 years and over was oversampled in order to get valid results, whereas for logistical reasons the very large subgroup of persons younger than 50 years with ID due to other causes than Down's syndrome was undersampled. Institutional review board approval and informed consent were obtained for every participant. As a result of privacy considerations, the informed consent procedure was locally organised by the ID services in all cases, and supported by the research team. Through contact persons, the legal representatives were approached for written informed consent. Consent could be given for both file assessment and screening, or for file assessment alone. Clients who were able to communicate verbally, were informed by staff or family members according to their comprehensive capabilities and asked for their written or spoken consent.

\section{Methods}

After checking the medical records for cause and severity of ID (criteria of the American Association on Mental Retardation $^{14}$ ) and ophthalmological history, protocollised assessment of visual functioning was performed on-site in one session. In all, $45 \mathrm{~min}$ were available for each complete screening. ${ }^{15}$ Sampling and assessment were performed between September 1998 and January 2002. Visual impairment and blindness were diagnosed according to WHO-criteria (visual impairment: visual acuity $<0.30$, but not $<0.05$ and/or visual fields $<30^{\circ}$ around central fixation point; blindness: visual acuity $<0.05$ and/or visual fields $<10^{\circ}$ ). Both presenting and best-corrected visual acuity were assessed; best-corrected visual acuity was used in the analyses. In practice, in this population, bestcorrected visual acuity implied with new correction, if necessary and accepted by the patient, and otherwise presenting visual acuity. Reliability of visual acuity measurement was increased by the use of more than one assessment method, specially trained investigators and measurement of the inter-rater reliability. With every participant, preferably two of the following visual acuity tests were used: tests based on recognition (Snellen's chart, ${ }^{16}$ Burghardt's children's chart, Stycar single characters and matching ${ }^{17}$ ) and tests based on pattern resolution (Cardiff Acuity Cards ${ }^{18}$ and Teller Acuity Cards ${ }^{19}$ ). Acuity measurements based on recognition and pattern resolution are not exactly comparable. ${ }^{20}$

However, as it turned out, the number of participants requiring pattern resolution tests was very small in the group with mild and moderate ID, whereas the number that could be assessed with recognition acuity tests was very small in the group with severe and profound ID. Therefore all outcomes were expressed in Snellen equivalents. $^{21}$

Inter-rater reliability: the inter-rater reliability of the three examiners was tested with 30 participants each. No deviations were found to indicate that the classification of visual impairment should be adjusted.

Refraction was determined with the Nikon Retinomax K-plus Autorefractometer (Nikon Instruments Inc., Melville, New York, USA), or by retinoscopy. Since cycloplegic eyedrops had a strong adverse effect on the cooperation in a pilot group of 20 participants, these were removed from the protocol. To compensate for this, the testing rooms were made as dark as possible, in order to relax accommodation. Assessment of the visual fields was performed with the Stycar graded balls confrontational method. ${ }^{22}$

\section{Analyses}

All data were stored in Access 97 (Microsoft Corporation, Redmond, USA) and analysed with SPSS version 10.0 (SPSS Inc., Chicago, IL, USA). The independent relationships between visual impairment or blindness, on the one hand, and Down's syndrome, degree of ID and age $50+$ years, on the other hand, were evaluated by means of multiple logistic regression analysis. A multiple imputation technique, ${ }^{23}$ using all relevant information, was applied to compensate for participants not included in the analysis.

The prevalence of visual impairment and blindness found could not be directly extrapolated to the whole adult population with ID in the Netherlands, because the 
sample we assessed was stratified. It could, however, be assumed that the composition of the base population of 9012 adults was a reliable reflection of the total population of Dutch service users. ${ }^{24,25}$ Therefore a weighted prevalence was computed from the figures found in the $2 \times 2 \times 2$ cells: age $50-/ 50+$, Down's syndrome $-/+$, institutionalised/community care (direct standardisation).

\section{Results}

\section{Population}

Details on consent and participation have been published elsewhere. ${ }^{13}$ No consent was obtained for 634 clients and the consent procedure was stopped because of unacceptable delays in a very large community-based organisation: this accounted for 362 lost cases. Consent was obtained from 1598 clients, of whom 1539 actually took part in the visual screening. The composition of this population is shown in Table 1. There were 862 males $(56.0 \%)$; age range was 20.2-88.7 years (mean age 45.7 years). As a result of the final under-representation of clients from community-based services, a majority of participants $(1133 / 1598=70.9 \%)$ were institutionalised, leading to an overrepresentation of more severe degrees of ID (Table 1).

\section{Prevalence and severity of visual impairment and blindness}

Reproducible and complete determination of visual function (visual acuity and visual field testing) was possible in $1358 / 1539$ cases $(88.2 \%)$. Among the 181 'dropouts' no over- or under-representation of the risk factors (age 50+, Down's syndrome, severe ID) was found. Visual impairment was diagnosed found in
183/1358 (13.5\%; 95\% confidence interval (CI), 11.7-15.4), blindness in 78/1358 (5.7\%; 95\% CI, 4.6-7.1). Multiple imputation $^{23}$ yielded higher prevalences for the total study population of 1598 participants for both visual impairment $(16.8 \%$; 95\% CI, 8.4-25.2) and blindness (5.8\%; 95\% CI, 4.2-7.4). Visual problems had not been recognised prior to the present study in 106/261 (40.6\%) persons: visual impairment not in 78/183 (42.6\%) and blindness not in $28 / 78$ persons (35.9\%).

Relationship of visual impairment to age above 50 years, Down's syndrome and degree of ID

Tables 2 and 3 present the prevalences of visual impairment and blindness in the different subgroups. Prevalences of visual impairment increased from $2.2 \%$ in young persons with mild ID due to other causes than Down's syndrome to $66.7 \%$ in people aged 50 years and older, with Down's syndrome and profound intellectual disabilities. Blindness was most prevalent in people under 50 years with profound ID due to other causes than Down's syndrome. Table 4 presents the outcome of multiple logistic regression with visual impairment, including blindness, as dependent variable. A significant interaction was shown between Down's syndrome and age $(P<0.0005)$, which is also obvious in Table 2 .

Therefore stratified analysis was applied to the group with and the group without Down's syndrome (Table 4). Prevalence of visual impairment had a strong linear relationship with degree of intellectual disability in the group without Down's syndrome, whereas the association with advancing age was less obvious. In contrast, in the group with Down's syndrome, visual impairment had a stronger relationship with advancing age and a less obvious relationship with the degree of intellectual disability.

Table 1 Composition of the studied population $(N=1539)$

\begin{tabular}{|c|c|c|c|c|c|c|}
\hline Age & Down's syndrome absent & $\%$ & Down's syndrome present & $\%$ & Total & $\%$ \\
\hline \multicolumn{7}{|l|}{ Subjects $<50$} \\
\hline Mild ID (IQ 55-70) & 146 & 9.4 & 23 & 1.5 & 169 & 11.0 \\
\hline Moderate ID (IQ 35-55) & 258 & 16.8 & 141 & 9.2 & 399 & 25.9 \\
\hline Severe ID (IQ 25-35) & 145 & 9.4 & 55 & 3.6 & 200 & 13.0 \\
\hline Profound ID (IQ < 25) & 106 & 6.9 & 18 & 1.2 & 124 & 8.1 \\
\hline Unknown & 55 & 3.6 & 14 & 0.9 & 69 & 1.5 \\
\hline Total & 710 & 46.1 & 251 & 16.3 & 961 & 62.4 \\
\hline \multicolumn{7}{|l|}{ Subjects $\geq 50$} \\
\hline Mild ID (IQ 55-70) & 79 & 5.1 & 7 & 0.5 & 86 & 5.6 \\
\hline Moderate ID (IQ 35-55) & 172 & 11.2 & 70 & 4.5 & 242 & 15.7 \\
\hline Severe ID (IQ 25-35) & 82 & 5.3 & 44 & 2.9 & 126 & 8.2 \\
\hline Profound ID (IQ < 25) & 43 & 2.8 & 25 & 1.6 & 68 & 4.4 \\
\hline Unknown & 44 & 2.8 & 12 & 0.8 & 56 & 3.6 \\
\hline Total & 420 & 27.3 & 158 & 10.3 & 578 & 37.6 \\
\hline
\end{tabular}

ID: intellectual disability; IQ: intelligence quotient. 
Table 2 Prevalence (\%) of visual impairment (WHO) by age, level of ID and Down's syndrome $\pm(N=1358)$

\begin{tabular}{lcrrr}
\hline Age & $\begin{array}{c}\text { Down's } \\
\text { syndrome } \\
\text { absent } \\
(\mathrm{N}=623)\end{array}$ & \multicolumn{3}{c}{$\begin{array}{c}\text { c5ndrome } \\
\text { present } \\
(\mathrm{N}=227)\end{array}$} \\
\hline Subjects $<50$ & & & & \\
$\quad$ Mild ID & 2.2 & $0.5-6.4$ & 4.8 & $0.1-23.8$ \\
Moderate ID & 3.9 & $1.8-7.3$ & 6.2 & $2.7-11.8$ \\
Severe ID & 19.4 & $12.8-27.4$ & 22.9 & $12.0-37.3$ \\
Profound ID & 28.8 & $19.2-40.0$ & 28.6 & $8.4-58.1$ \\
Unknown & 1.9 & $0.1-10.1$ & 14.3 & $1.8-42.8$ \\
Total & 9.6 & $7.4-12.2$ & 11.5 & $7.6-16.3$ \\
& & & & \\
Subjects $\geq 50$ & $(\mathrm{~N}=373)$ & & & \\
$\quad$ Mild ID & 8.3 & $3.1-17.3$ & 20.0 & $0.5-74.6$ \\
Moderate ID & 10.8 & $6.4-16.8$ & 25.0 & $15.0-37.4$ \\
Severe ID & 22.7 & $13.8-33.8$ & 36.1 & $20.8-53.8$ \\
Profound ID & 39.3 & $21.5-59.4$ & 66.7 & $41.0-86.7$ \\
Unknown ID & 2.4 & $0.1-12.9$ & 25.0 & $5.5-57.2$ \\
Total & 14.2 & $10.6-17.9$ & 33.3 & $25.5-42.0$ \\
\hline
\end{tabular}

ID: intellectual disability; 95\% CI: 95\% confidence interval.

Table 3 Prevalence (\%) of blindness (WHO) by age, level of ID and Down's Syndrome $\pm(N=1358)$

\begin{tabular}{|c|c|c|c|c|}
\hline Age & $\begin{array}{c}\text { Down's } \\
\text { syndrome } \\
\text { absent } \\
(\mathrm{N}=623)\end{array}$ & $95 \% \mathrm{CI}$ & $\begin{array}{c}\text { Down's } \\
\text { syndrome } \\
\text { present } \\
(\mathrm{N}=227)\end{array}$ & $95 \% \mathrm{CI}$ \\
\hline \multicolumn{5}{|l|}{ Subjects $<50$} \\
\hline Mild ID & 0.7 & $0.1-4.1$ & 0.0 & $0.0-16.0$ \\
\hline Moderate ID & 2.2 & $0.7-5.0$ & 0.0 & $0.0-2.8$ \\
\hline Severe ID & 4.0 & $1.3-9.2$ & 4.2 & $0.5-14.3$ \\
\hline Profound ID & 38.9 & $28.1-50.3$ & 28.6 & $8.4-58.1$ \\
\hline Unknown & 5.7 & $11.8-15.7$ & 0.0 & $0-23.1$ \\
\hline Total & 7.2 & $5.3-9.5$ & 2.6 & $0.9-5.7$ \\
\hline & $(\mathrm{N}=373)$ & & $(\mathrm{N}=135)$ & \\
\hline \multicolumn{5}{|l|}{ Subjects $\geq 50$} \\
\hline Mild ID & 2.8 & $3.4-9.7$ & 0.0 & $0.0-52.2$ \\
\hline Moderate ID & 2.5 & $0.7-6.4$ & 3.1 & $0.3-10.8$ \\
\hline Severe ID & 6.7 & $2.2-14.9$ & 13.9 & $4.7-29.5$ \\
\hline Profound ID & 17.9 & $6.1-36.9$ & 16.7 & $3.6-41.4$ \\
\hline Unknown & 2.4 & $0.1-12.9$ & 0.0 & $0.0-26.4$ \\
\hline Total & 4.6 & $0.3-7.2$ & 7.4 & $3.6-13.2$ \\
\hline
\end{tabular}

ID: intellectual disability; 95\% CI: 95\% confidence interval.

\section{Generalisation of the results to the total Dutch population with ID}

Computation of the weighted prevalences resulted in population prevalences of $13.8 \%$. (95\% CI, 9.3-18.4) for visual impairment and 5.0\% (95\% CI, 3.8-6.2) for blindness (Table 5). For the total population of around 75000-87000 adult ID service users in the
Table 4 Summary of multiple logistic regression model with visual impairment, including blindness (WHO), as the dependent variable

\begin{tabular}{|c|c|c|c|}
\hline Parameter & Odds ratio & $\begin{array}{c}95 \% \\
\text { confidence } \\
\text { interval }\end{array}$ & P-value \\
\hline \multicolumn{4}{|l|}{ Down's syndrome absent } \\
\hline Degree of ID: mild & - & - & - \\
\hline Degree of ID: moderate & 1.57 & $0.80-3.10$ & 0.227 \\
\hline Degree of ID: severe & 5.58 & $2.87-10.85$ & $<0.0005$ \\
\hline Degree of ID: profound & 32.10 & 15.77-65.36 & $<0.0005$ \\
\hline Age $50+$ (years) & 1.60 & $1.07-2.38$ & 0.010 \\
\hline \multicolumn{4}{|l|}{ Down's syndrome present } \\
\hline Degree of ID: mild & - & - & - \\
\hline Degree of ID: moderate & 1.51 & $0.33-6.98$ & 0.600 \\
\hline Degree of ID: severe & 5.52 & $1.18-25.86$ & 0.030 \\
\hline Degree of ID: profound & 23.55 & $4.40-126.10$ & $<0.0005$ \\
\hline Age $50+$ (years) & 4.08 & $2.28-7.29$ & $<0.0005$ \\
\hline
\end{tabular}

ID: Intellectual disability.

Netherlands, ${ }^{24,25}$ this would signify that between 14000 and 16000 adults with ID are visually impaired or blind.

\section{Discussion}

This is the first population-based epidemiological study of visual impairment and blindness in a population with the full spectrum of ID. It covered a random sample of adult users of Dutch intellectual disability services, large enough to obtain valid population prevalences and allow valid identification of specific risk groups. The prevalence of visual impairment, diagnosed according to WHO-criteria, varied from $2.2 \%$ in the least affected subgroup (young adults with mild ID through other causes than Down's syndrome) up to $66.7 \%$ in the most affected subgroup (participants aged 50 years or older, with Down's syndrome and profound ID). The prevalence of blindness varied between $0.7 \%$ (young adults with mild ID through other causes than Down's syndrome) and $38.9 \%$ (young adults with profound ID through other causes than Down's syndrome). In $40.6 \%$ of the cases with visual impairment or blindness, the diagnosis had not been made prior to this study.

Severe or profound ID considerably increased the risk of visual impairment and blindness. In fact, adults with severe or profound ID may be considered visually impaired until proved otherwise. The same pertains to older adults with Down's syndrome. In people aged 50 years and older, Down's syndrome was the strongest risk factor. As a result of over- and under-sampling, incomplete inclusion and loss to participation, prevalences found in the total study population $(16.8 \%$ for visual impairment and $5.8 \%$ for blindness) our study 
Table 5 Extrapolation of current results to base population $(N=9012)$

\begin{tabular}{|c|c|c|c|c|c|c|c|c|}
\hline Base population & 9012 & $\begin{array}{c}\mathrm{N} / 9012 \\
(\%)\end{array}$ & $\begin{array}{c}\text { Visual } \\
\text { impairment } \\
\text { per group }\end{array}$ & $\begin{array}{c}\text { Extrapolation } \\
\text { to base } \\
\text { population }\end{array}$ & $\begin{array}{c}\text { Total } \\
\text { prevalence }(\%)\end{array}$ & $\begin{array}{l}\text { Blindness } \\
\text { per group } \\
\quad(\%)\end{array}$ & $\begin{array}{c}\text { Extrapolation } \\
\text { to base } \\
\text { population }\end{array}$ & $\begin{array}{c}\text { Total } \\
\text { prevalence } \\
(\%)\end{array}$ \\
\hline Down's syndrome- & 7399 & 82.1 & & & & & & \\
\hline Institutionalized & 4074 & 45.2 & & & & & & \\
\hline Age $<50$ & 3042 & 33.8 & $15.3 \%$ & $0.338 \times 15.3$ & 5.17 & 8.8 & $0.338 \times 8.8$ & 2.97 \\
\hline Age $\geq 50$ & 1032 & 11.5 & $20.0 \%$ & $0.115 \times 20.0$ & 2.30 & 6.0 & $0.115 \times 6.0$ & 0.69 \\
\hline Community care & 3325 & 36.9 & & & & & & \\
\hline Age $<50$ (years) & 2364 & 26.2 & $7.4 \%$ & $0.262 \times 7.4$ & 1.94 & 2.1 & $0.262 \times 2.1$ & 0.55 \\
\hline Age $\geq 50$ (years) & 961 & 10.7 & $10.0 \%$ & $0.107 \times 10.0$ & 1.07 & 2.2 & $0.107 \times 2.2$ & 0.24 \\
\hline Down's syndrome + & 1613 & 17.9 & & & & & & \\
\hline Institutionalized & 772 & 8.6 & & & & & & \\
\hline Age $<50$ (years) & 594 & 6.6 & $18.1 \%$ & $0.066 \times 18.1$ & 1.19 & 4.4 & $0.066 \times 4.4$ & 0.29 \\
\hline Age $\geq 50$ (years) & 178 & 2.0 & $36.0 \%$ & $0.020 \times 36.0$ & 0.72 & 9.4 & $0.020 \times 9.4$ & 0.19 \\
\hline Community care & 841 & 9.3 & & & & & & \\
\hline Age $<50$ (years) & 643 & 7.1 & $9.5 \%$ & $0.071 \times 9.5$ & 0.67 & 0.0 & $0.071 \times 0.0$ & 0.00 \\
\hline Age $\geq 50$ (years) & 198 & 2.2 & $34.7 \%$ & $0.022 \times 34.7$ & $\begin{array}{c}0.76 \\
13.82 \\
\langle 9.3-18.4\rangle^{\mathrm{b}}\end{array}$ & 3.7 & $0.022 \times 3.7$ & $\begin{array}{c}0.08 \\
5.01 \\
\langle 3.8-6.2\rangle^{\mathrm{b}}\end{array}$ \\
\hline
\end{tabular}

aprevalence calculated after imputation.

${ }^{\mathrm{b}} 95 \%$ confidence interval.

population was skewed towards older age and Down's syndrome. Therefore the found prevalences are not directly representative for the total population with ID. Nevertheless, the study population and its subgroups were large enough to apply computation of weighted prevalences, compensating for any bias in the prevalence estimate due to sampling, nonparticipation or noncooperation. Weighting our subgroup figures with the relative frequencies in the whole population of adult ID service users, resulted in population prevalences of $13.8 \%$ for visual impairment and 5.0\% for blindness, with satisfyingly narrow intervals.

Another point is, that the studied population consisted of users of ID services and did not include unregistered people with ID. A possible bias might have been the fact that our study population is selected from service users. We think the bias due to this lack of nonservice users is of limited effect. In the Netherlands, almost every person registered as intellectually disabled is a user of some kind of intellectual disability service. Only a small minority is living at home, not using any service. These are primarily persons with mild or borderline ID, in which we might expect that prevalences of visual impairment are much lower.

Although we did not find any significant overrepresentation of any of the investigated risk factors among those who did not cooperate sufficiently with the tests, any over-representation might have lead to an underestimation of the prevelances.

In order to reliably test as many participants as possible, we used methods based on both recognition and pattern resolution. Kushner et $a l^{26}$ concluded that pattern resolution tests might underestimate a specified level of visual impairment. This could mean that in the group tested this way, there were more participants with visual impairment than we found, which would make figures even more impressive.

Other authors studying visual impairment in the United Kingdom and the Netherlands, have also looked at differences between subgroups. Published studies are based on selected and smaller samples, hampering the application of good statistical evaluation and comparison with the general population. McCulloch et $a l^{27}$ assessed 63 institutionalised adults with ID. Their findings ranged from no visual impairment in people with mild ID up to almost $45 \%$ in the group with profound ID. Woodhouse et $a l^{9}$ assessed 154 adults with ID living in the community. They used a different classification for degree of ID and found significant differences in the prevalence of visual impairment between mild and more severe ID. Evenhuis et $a l^{10}$ assessed 672 institutionalised adults, using the same definitions as the present study, and found prevalence rates for visual impairment, including blindness, ranging from $4 \%$ (mild to moderate ID through other causes than Down's syndrome, age under 50 years) up to $78 \%$ (severe to profound ID, Down's syndrome, age over 50 years). Although an increased risk of visual impairment, at least for subgroups with more severe ID and Down's syndrome, was already suggested by these pioneering studies, their outcomes could not be generalised to the population with ID.

The most recent data on visual impairment and blindness according to WHO criteria in the general 
population in the Netherlands, were obtained from the ongoing Rotterdam Study. This population-based epidemiological study focusses on age-related conditions in adults aged 55 years and older. ${ }^{28}$ Visual impairment was found in $96 / 6775$ participants $(1.4 \%)$, blindness in $32 / 6775(0.5 \%)$. These figures are comparable with studies in the United States and Australia, although slightly different criteria were used. ${ }^{29,30}$ The present study results show that for young adults with mild ID and no Down's syndrome, the least affected subgroup, the risk of visual impairment is already higher than that in the general Dutch population above the age of 55 years, whereas the risk of blindness in this younger group is comparable to the risk in the general ageing population.

Because the risk of visual impairment is increased in all adult subgroups with ID, including those younger than 50 years, one may assume that part of the diagnosed visual impairment and blindness was congenital or acquired in early childhood. Prevalence of visual impairment in children in the general American population was recently published by Mervis et al. ${ }^{11}$ They used data from the Metropolitan Atlanta Developmental Disabilities Surveillance Program (MADDSP) and found an overall prevalence of 10.7 (95\% CI, 9.9-11.5) per 10000 children. Intellectual disability was found to be the most common coexisting disability $(58 \%)$, with a considerably higher risk in more severe ID. Age-related visual loss may be superimposed upon such congenital and earlier acquired impairments. Therefore, specific epidemiological research on visual impairment in children with ID, also evaluating implementation of routine early identification programmes in this group, is urgently needed. The International Association on the Scientific Studies in Intellectual Disabilities (IASSID) has stressed this point in an international consensus statement. $^{21}$

The high prevalence of unidentified visual impairment and blindness in Dutch adults with ID, however, notwithstanding the Dutch consensus on active detection of visual impairment in persons with $\mathrm{ID}^{21}$ subsequent skills courses in specific diagnostic methods and largescale screening programmes by district visual advisory centres, underscores the need of active screening in the adult group also.

\section{Acknowledgements}

This work was supported by Grant 940-33-029 of the Dutch Organization for Scientific Research (NWO), the Dr Fischer Foundation and De Bruggen Intellectual Disability Centre; Bartiméushage participated in the screening activities.
The authors have no commercial interest in any products described in this article.

\section{References}

1 Warburg M. Visual impairment in adult people with intellectual disability: literature review. J Intellect Disabil Res 2001; 45(Part 5): 424-438.

2 da Cunha RP, Moreira JB. Ocular findings in Down's syndrome. Am J Ophthalmol 1996; 122: 236-244.

3 Evans JR, Wachs H, Borger JM. A survey of visual skills of institutionalized retarded patients. Am J Ment Defic 1972; 76: 555-560.

4 Grunewald K (ed). Blind, deaf and physically handicapped mentally retarded. An epidemiological study as a base for action. Proceedings of the Third Congress of the International Association for the Scientific Study of Mental Deficiency, Copenhagen 1975 pp. 349-352.

5 Levy B. Incidence of oculo-visual anomalies in an adult population of mentally retarded persons. Am J Optom Physiol Opt 1984; 61: 324-326.

6 Courtney GR. Astigmatism among institutionalized and non-institutionalized mentally retarded. Am J Optom Physiol Opt 1977; 54: 347-350.

7 Sacks JG, Goren MB, Burke MJ, White SS. Ophthalmologic screening of adults with mental retardation. Am J Ment Retard 1991; 95: 571-574.

8 Warburg M. Visual impairment among people with developmental delay. J Intellect Disabil Res 1994; 38(Part 4): 423-432.

9 Woodhouse JM, Griffiths C, Gedling A. The prevalence of ocular defects and the provision of eye care in adults with learning disabilities living in the community. Ophthalmic Physiol Opt 2000; 20: 79-89.

10 Evenhuis HM, Theunissen M, Denkers I, Verschuure H, Kemme H. Prevalence of visual and hearing impairment in a Dutch institutionalized population with intellectual disability. J Intellect Disabil Res 2001; 45(Part 5): 457-464.

11 Mervis CA, Boyle CA, Yeargin-Allsopp M. Prevalence and selected characteristics of childhood vision impairment. Dev Med Child Neurol 2002; 44: 538-541.

12 Splunder van J, Stilma JS, Bernsen RMD, Evenhuis HM. Prevalence of ocular diagnoses found on screening 1539 adults with intellectual disabilities. Ophthalmology 2004; 111: 1457-1463.

13 Evenhuis HM, Splunder van J, Vink M, Weerdenburg C, Zanten van GA, Stilma JS. Obstacles in large-scale screening of sensory impairments in a population with intellectual disabilities. J Intellect Disabil Res 2004; 48(Part 8): 708-718.

14 Luckason R, Borthwick-Duffy S, Buntinx WHE, Coulter DL, Craig EM, Reeve A et al. (eds). Mental Retardation: Definition, Classification and System of Supports. AAMR: Washington DC, 2002.

15 Splunder van J, Stilma JS, Bernsen RMD, Arentz GMHJ, Evenhuis HM. Refractive errors in 900 adults with intellectual disabilities in the Netherlands. Acta Ophthalmol Scand 2003; 81: 123-129.

16 Snellen H. Letterproeven tot Bepaling der Gezigtsscherpte. PW van der Weijer: Utrecht, 1862.

17 Sheridan MD. Manual for the STYCAR vision tests. NFERNelson: Windsor, 1976. 
18 Woodhouse JM, Adoh TO, Oduwaiye KA, Batchelor BG, Megji S, Unwin $\mathrm{N}$ et al. New acuity test for toddlers. Ophthalmic Physiol Opt 1992; 12: 249-251.

19 Teller DY. The forced-choice preferential looking procedure: a psychological technique for use with human infants. Infant Behav and Dev 1979; 2: 135-153.

20 Warburg M. Visual impairment in adult people with moderate, severe, and profound intellectual disability. Acta Ophthalmol Scand 2001; 79: 450-454.

21 Evenhuis HM, Nagtzaam LMD (eds). International Association on the Scientific Studies in Intellectual Disabilities International Consensus Statement Early Identification of Hearing and Visual Impairment in Children and Adults with an Intellectual Disability. Manchester, 1998 IASSID Special Interest Research Group on Health Issues. Website: www.iassid.org.

22 Sheridan MD. The STYCAR graded-balls vision test. Dev Med Child Neurol 1973; 15: 423-432.

23 Rubin DB, Schenker N. Multiple imputation in health care databases: an overview and some applications. Stat Med 1991; 10: 585-598.

24 Koedoot PJ. Verstandelijke handicap. In: Maas IAM, Gijssen R, Lobbezoo IE, Poos MJJC (eds). Volksgezondheid Toekomst Verkenning 1997. Rijksinstituut voor Volksgezondheid en Milieu: Maarssen, 1997; 50-54.
25 van Schrojenstein Lantman-de Valk HM, van Heurn-Nijsten EWA, Wullink M, Zinzen-Turkenburg BAM

Prevalentieonderzoek Mensen met een verstandelijke beperking in Nederland. Universiteit Maastricht: Maastricht, 2002.

26 Kushner BJ, Lucchese NJ, Morton GV. Grating visual acuity with Teller cards compared with Snellen visual acuity in literate patients. Arch Ophthalmol 1995; 113(4): 485-493.

27 McCulloch DL, Sludden PA, McKeown K, Kerr A. Vision care requirements among intellectually disabled adults: a residence-based pilot study. J Intellect Disabil Res 1996; 2: 140-150.

28 Klaver CCW, Wolfs RCW, Vingerling JR, Hofmann A, De Jong PTVM. Age-specific prevalence and causes of blindness and visual impairment in an older population. Arch Ophthalmol 1998; 16: 653-658.

29 Rahmani B, Tielsch JM, Katz J, Gottsch J, Quigley H, Javitt J et al. The cause-specific prevalence of visual impairment in an urban population. The Baltimore Eye Survey. Ophthalmology 1996; 103: 1721-1726.

30 Van Newkirk MR, Weih L, McCarty CA, Taylor HR. Causespecific prevalence of visual impairment in Victoria, Australia: the Visual Impairment Project. Ophthalmology 2001; 108: 960-967. 